\title{
Performance evaluation of novel surface flame self-aspirated porous radiant burners for cooking applications
}

\author{
PREMANANDA PRADHAN $^{1}$ and PURNA CHANDRA MISHRA ${ }^{2, *}$ \\ ${ }^{1}$ Faculty of Engineering and Technology, ITER, Siksha 'O' Anusandhan Deemed to be University, \\ Bhubaneswar 751030, India \\ ${ }^{2}$ School of Mechanical Engineering, KIIT Deemed to be University, Bhubaneswar 751024, India \\ e-mail: pradhanpremananda@gmail.com; pcmishrafme@kiit.ac.in
}

MS received 28 December 2016; revised 18 May 2018; accepted 7 June 2018; published online 12 September 2018

\begin{abstract}
Porous radiant burners (PRBs) are based on the principle of porous media combustion (PMC) in which both combustion and stabilization of the flame take place towards the end of combustion zone (CZ). It has lot of advantages over conventional free flame burners. The porous matrix has high thermal conductivity and high emissivity. Hence, contributions to conduction, convection and radiation in the PMC are significant. This paper presents experimental results on the thermal and emission performance of newly developed, bi-layered, self-aspirated porous radiant surface flame burners used in cooking applications. It comprises firebrick material in the $\mathrm{CZ}$ and steel balls in the preheating zone (PZ). Performance of this burner is compared to that of a conventional cooking burner (CB) within the operating range of $0.5-2 \mathrm{~kW}$. The effect of burner geometry (one is circular and the other one is square in cross section) on the thermal performance and emission using liquefied petroleum gas (LPG) as the fuel is also studied and their thermal performances are compared to the conventional ones. The experimental results have revealed that the thermal efficiencies of circular and square PRBs are much higher than those of the conventional burner. The maximum thermal efficiency of the self-aspirated circular porous radiant burner (SCPRB) is found to be $71.78 \%$ at the flow rate $(V)$ of $2.0 \mathrm{~m} / \mathrm{s}$ with a porosity of $85 \%$, whereas the thermal efficiency obtained from self-aspirated square porous radiant burner (SSPRB) is marginally less than that of SCPRB at the corresponding flow rate and porosity. The emission levels are much lower in these novel PRBs as compared with the conventional burner and these values are well below the World Health Organization (WHO) standard. The $\mathrm{NO}_{x}$ emission values corresponding to the optimum velocity of $2.0 \mathrm{~m} / \mathrm{s}$ are $87 \mathrm{ppm}$ for CB, and 24 and $27 \mathrm{ppm}$, respectively, for SCPRB and SSPRB. CO emission values are 32, 33 and $155 \mathrm{ppm}$ for SCPRB, SSPRB and CB, respectively, corresponding to the optimum velocity of flow.
\end{abstract}

Keywords. Porous surface burner; self-aspirating; IR thermography; LPG; thermal efficiency; emission.

\section{Introduction}

The heating systems used for cooking purposes that operate on free flame lead to relatively low thermal efficiency and high emission due to lower heat transfer coefficient, incomplete combustion and thin reaction zone. On the other hand, porous radiant burners (PRBs) have high thermal efficiency and these burners are capable of reducing emission due to large heat transfer coefficient, high peak flame temperature and improved combustion. PRBs based on porous media combustion (PMC) technology are classified into two groups based on the position of flame stability and combustion. In matrix-stabilized PRBs, the stabilization of the flame as well as the combustion takes place completely within the porous matrix, and in surfacestabilized PRBs, both the combustion and the flame

*For correspondence stabilization occur downstream of the combustion zone (CZ). Although matrix-stabilized PRBs have lot of advantages over surface-stabilized PRBs, the former is suitable for applications that needs high power intensities whereas the application of the latter is limited to a power intensity of $400 \mathrm{~kW} / \mathrm{m}^{2}$. Hence surface-stabilized PRBs are suitable for domestic use [1,2].

It was observed that the research works [1-4] were concentrated on developing domestic liquefied petroleum gas (LPG) cooking burners (CBs) using PMC technology. They got an efficiency as high as $75 \%$ with a very low emission of $\mathrm{CO}$ and $\mathrm{NO}_{x}$ and power intensity of $0.5-3.0 \mathrm{~kW}$ for fuel lean combustion controlling air flow to the mixing chamber.

Fuel-rich combustion is generally expected in naturally aerated or self-aspirated burners. Jugjai et al [5] used swirling central flame technique in a conventional LPG gas burner and obtained about 3\% higher efficiency than the 
conventional one. Namkhat and Jugjai [6] studied the primary air entrainment characteristics for a self-aspirating conventional burner. They have observed that the combustion temperature, the appearance of the flame (oxidized or diffused) and its stability are affected by thermal input (flow rate of fuel) and primary aeration. They have also demonstrated that an increase in the rate of reaction and a decrease in primary aeration are obtained if the air is preheated before mixing with the fuel. Jugjai and Rungsimuntuchart [7] used the principle of PMC and recirculation in domestic $\mathrm{CB}$ with a higher input range and developed a novel semi-confined porous radiant recirculation burner (PRRB). They obtained an efficiency of $60 \%$ with compatible emission. Yoksenakul and Jugjai [8] designed and developed a self-aspirated porous medium burner and reported $4.58 \%$ more efficiency than the conventional burner at an equal firing rate. They observed that thermal efficiencies of both the burners decreased with an increase in firing rate and distance between the burner top and the bottom of the loading vessel. For this burner, $\mathrm{NO}_{x}$ emission was around $59 \mathrm{ppm}$, but the $\mathrm{CO}$ emission was little higher than that of the conventional burner due to the lack of secondary air entrainment and incomplete combustion.

In this paper, experimental analysis of a novel selfaspirated porous surface burner used in domestic cooking is presented. Thermal performances of this burner are compared to those of a conventional free flame $\mathrm{CB}$ within the power range of $0.5-2 \mathrm{~kW}$. This self-aspirated, twolayered $\mathrm{PRB}$ is composed of firebrick material in the $\mathrm{CZ}$ and layers of steel balls in the PZ. Two different geometries (one circular and other square in cross section) are considered for the test to study the effect of geometry on thermal performances. Five different fuel flow velocities within the afore-mentioned power operating range are taken as input parameters. Novelty in the burner is the use of firebrick ceramic as a material in the $\mathrm{CZ}$. The concept of improving the performance with the use of better heat conducting material in the PZ compared with $\mathrm{CZ}$ further added feathers to the beauty of these burners. Secondary air entrainment to the burner to control $\mathrm{NO}_{x}$ and $\mathrm{CO}$ is another novelty of this burner.

\section{Experimental set-up and procedure}

\subsection{Experimental set-up}

A schematic of the experimental set-up used for testing the performance of both conventional burner and PRBs is shown in figure 1 . The experimental set-up is very flexible and consists of a digital weighing scale with a resolution of $2 \mathrm{~g}$ for measuring mass flow rate of LPG. A 14.2-kg LPG

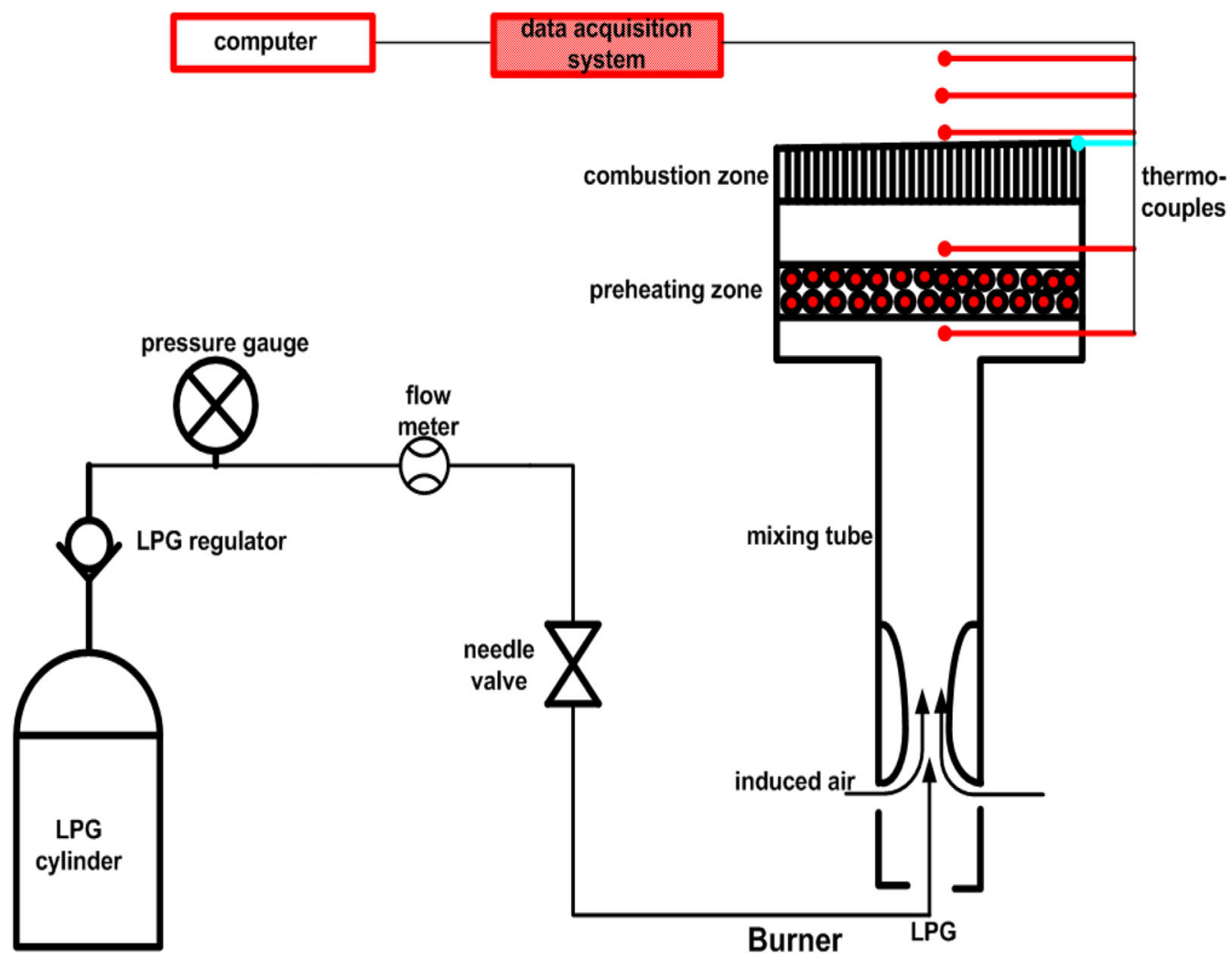

Figure 1. Schematic of experimental set-up. 
cylinder supplied by HPCL with flexible hoses of $12.7 \mathrm{~mm}$ internal diameter is used to supply fuel to the burners. The volume flow rate was measured using an acrylic body LPG rotameter (Make: FLOWPOINT, India). It was placed before the fuel nozzle to measure the volume flow rate of the fuel from the cylinder. A bourdon tube pressure gauge was used for measuring pressure of the gas in the cylinder.

The temperature of the atmosphere and the flame above the burner was measured by four K-type thermocouples. They were arranged both vertically and horizontally on the top of the burner surface. In addition to these four thermocouples, two more thermocouples (one in the interfacial gap between $\mathrm{CZ}$ and $\mathrm{PZ}$ and the other one was placed very close to the $\mathrm{PZ}$ ) were attached to measure the temperature distribution, prior to $\mathrm{CZ}$ and $\mathrm{PZ}$, respectively. The temperature data were acquired by a data acquisition system (Make: CHINO, India, Model: KR2000) with the ZAILA application software. An IR thermograph camera (Make: FLUKE, USA, Model: Ti32) was used to measure the contribution of radiation from the surface and to recognize the higher temperature location in the flame. The thermocouple data were stored in a computer and analysed in the Smart View application software environments. The fuel velocity was measured using a hot wire anemometer. The emission parameters $\left(\mathrm{CO}, \mathrm{CO}_{2}, \mathrm{HC}, \mathrm{NO}_{x}\right.$ and $\left.\mathrm{O}_{2}\right)$ of the burners were measured using a flue gas analyser (Make: AVL DITEST, India, Model: SCOPE 8400) and the measured data were processed in the SCOPE application software environments.

\subsection{Experimental procedure}

Experiments were conducted in both controlled and open atmosphere following BIS: 4246:2002 guidelines, and five different fuel velocities, i.e., $0.4,1.0,2.0,3.0$ and $3.6 \mathrm{~m} / \mathrm{s}$, were considered as input parameters within the range of 0.5-2.0 kW (operating range of domestic CBs) [1]. At the beginning, the LPG cylinder was placed on the digital weighing scale. Then the fuel regulating valve (non-return valve) was opened and the fuel was allowed to reach the second control valve through a pressure gauge and a rotameter. Regulating the second control valve, LPG was allowed to flow through the ejector and the velocity of flow was adjusted by placing the hot wire anemometer close to the ejector tip. Corresponding to a flow velocity, all the readings such as the pressure of the gas in cylinder, initial weight of the cylinder with the gas $\left(W_{1}\right)$ and volume flow rate from the rotameter were recorded. Then an aluminium vessel with known weight and 51 of water was placed on the burner. Initial temperature of water $\left(t_{1}\right)$ was noted before placing the vessel on the burner. Water was continuously stirred to maintain uniformity of temperature till it reached $90^{\circ} \mathrm{C}$. Finally, fuel supply to the burner was stopped and weight of the gas with cylinder $\left(W_{2}\right)$ was noted. Time taken for each set of operation was also recorded using a digital stopwatch. Mass of the fuel consumed during each set of operation is calculated by taking the difference between initial and final weight of the cylinder. For each set of operation, transient temperature data were recorded and saved in the data acquisition system. For each velocity of flow, five sets of observations were taken with emission data and the same procedure was repeated for all other velocities of flow.

\subsection{Instrumental and experimental uncertainties}

Instrumental uncertainties are the fixed errors and are obtained from the technical specifications. The volume flow rate was measured using the acrylic body LPG rotameter with an accuracy of $\pm 2 \%$ of full scale division (FSD), range of 0-12 lpm and resolution of $0.5 \mathrm{lpm}$. The temperature data were assessed by the data acquisition system with reference junction compensation accuracy of $\pm 0.5^{\circ} \mathrm{C}$ and high speed of sampling accuracy of $\pm 0.1 \%$. Also, the surface temperature of the burner was measured using the IR camera (FLUKE make) within a range of temperature measurement from 20 to $600^{\circ} \mathrm{C}$ with an accuracy of $\pm 2^{\circ} \mathrm{C}$ or $2 \%$. A hot wire anemometer was used to measure the velocity of the flow of fuel in the velocity measurement range of $0.1-25.0 \mathrm{~m} / \mathrm{s}$ and resolution of $0.01 \mathrm{~m} / \mathrm{s}$ with an accuracy of $\pm(5 \%+1 \mathrm{~d})$ reading and temperature measuring range of $0-50^{\circ} \mathrm{C}$ with a resolution of $0.1^{\circ} \mathrm{C}$ and an accuracy of $\pm 1{ }^{\circ} \mathrm{C}$. A digital weighing scale with a resolution of $1 \mathrm{~g}$ with an accuracy of $\pm 2 \mathrm{~g}$ was used to measure mass flow rate of LPG. A flue gas analyser (AVL DITEST) was used to measure $\mathrm{CO}, \mathrm{CO}_{2}, \mathrm{HC}, \mathrm{NO}_{x}$ and $\mathrm{O}_{2}$ emissions from the flue. For the measurement of the dimensions of the pores, a profile projector [Model: Metzer M, 806A, horizontal floor type] with ranges of magnifications as $10 \times$, $20 \times$ and $50 \times$ lens and an accuracy of $\pm 0.1 \%$ was used. It has a surface illuminator with an accuracy of $\pm 0.15 \%$. Errors in the measured parameters were obtained by repeating the tests for at least five times and the uncertainty in experimental results was estimated using the method proposed by Kline and Mc Flintlock [9] as it was based on the specifications of the uncertainties in the various primary experimental measurements. The uncertainty in test results was computed using Eq. (1):

$$
W_{r}=\left[\sum\left(\frac{\partial R}{\partial X_{i}}\right)^{2}\right]^{0.5}
$$

where $R^{\prime}$ ' is a given function of the independent variables $X_{1}, X_{2}, \ldots, X_{n} ; W_{r}$ is the uncertainty in the result and $W_{i}$ is the uncertainty in the independent variables [10].

The uncertainty in maximum surface temperature is found to be $\pm 4^{\circ} \mathrm{C}$. The uncertainty in thermal efficiency is around $\pm 2.34 \%$ corresponding to the optimum input velocity of $2 \mathrm{~m} / \mathrm{s}$ and is shown in figure 7 . 


\section{Characterization of burners}

\subsection{Self-aspirated conventional $C B$}

A locally available conventional CB (commercial burner), shown in figure 2, was considered for characterization in terms of its geometric parameters such as burner diameter, thickness, pore diameter, number of pores and pore array pattern, and inner diameter and length of the mixing tube. All these parameters are listed in table 1. This type of burner has a vertical set-up and power rating between 2 and $5 \mathrm{~kW}$. Diameter of the pores on the burner port was measured using a digital profile projector [Model: Metzer M, 806A, horizontal floor type].

\subsection{The novel self-aspirating porous radiant burners (SAPRBS)}

A schematic of the two newly designed and fabricated SAPRBs is depicted in figure 3. In designing the new burners, the measured characteristics of the conventional self-aspirated burners as well as radiant surface burners from the open literature were taken as the reference data. The body of the burners was made up of mild steel of thickness $3 \mathrm{~mm}$ for providing stability to the burners. It consisted of different components such as ceramic matrix, stainless-steel balls of different diameters (5 and $3 \mathrm{~mm}$ ), wire mesh and supporting frame. A supporting frame was used in the PZ to support the steel balls and a ceramic

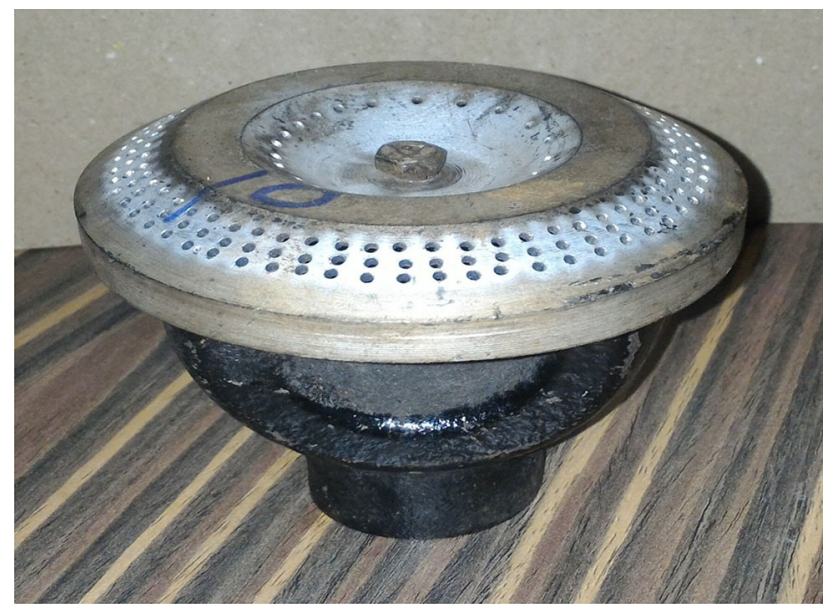

Figure 2. Photographic view of the conventional burner used in the study. matrix with different thicknesses and porosities was used in the CZ. The properties of ceramic material used as burner matrix are listed in table 2. Two different geometries of PRBs were fabricated to compare the effect of geometries on the performance of the burners, one was circular and other one was square in cross section. The self-aspirated circular porous radiant burner (SCPRB) had a diameter of $80 \mathrm{~mm}$ and a height of $65 \mathrm{~mm}$ and the self-aspirated square porous radiant burner (SSPRB) had $80 \mathrm{~mm}$ side with $65 \mathrm{~mm}$ height. Except for the shapes, all other conditions remain the same for both the burners. The ceramic matrix was tested with different thicknesses and porosities as depicted in table 3. The air-fuel mixing tube attached to the burner has an inner diameter of $40 \mathrm{~mm}$ and thickness of $3 \mathrm{~mm}$ with a length of $110 \mathrm{~mm}$. Grooves are made inside the supporting frame for fixing different layers of the burners. An interfacial gap of $12-15 \mathrm{~mm}$ was maintained between $\mathrm{CZ}$ and $\mathrm{PZ}$ to reduce the effect of excess preheating of the mixture on the thermal performance. Temperature within the interfacial gap and in the mixing tube close to the PZ were also measured for analysing the effect of preheating and reaction zone temperatures, which could help further in modifying the performance of the burners.

The design of the burners was based on the principle of preheating and internal recirculation to produce excess enthalpy and to increase peak temperature of the flame in

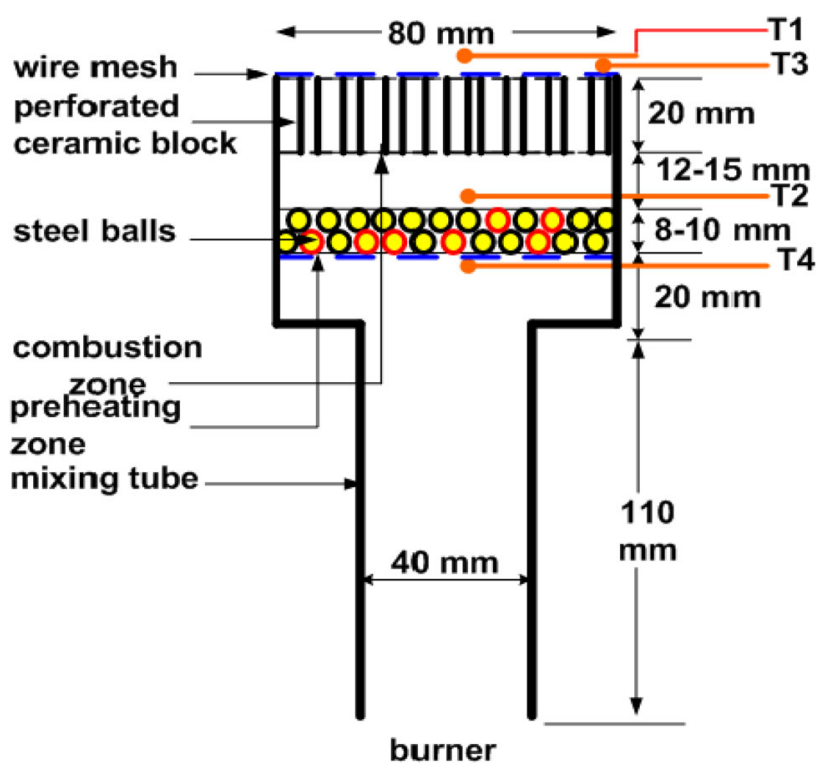

Figure 3. Schematic of the novel porous radiant burner.

Table 1. Characteristics of conventional porous burners.

\begin{tabular}{lccccc}
\hline Burner type & Outer dia. $(\mathrm{mm})$ & Thickness $(\mathrm{mm})$ & No. of pores & Pore size (mm) & Material \\
\hline Commercial & 114.42 & 6.0 & $60 \times 3+22=202$ & 2.61 & CI \\
\hline
\end{tabular}


Table 2. Properties of insulating light weight ceramic fire brick.

\begin{tabular}{|c|c|c|c|}
\hline Thermo-physical properties & Value & Chemical composition & Concentration $(\%)$ \\
\hline Bulk density & $604 \mathrm{~kg} / \mathrm{m}^{3}$ & Alumina & 37 \\
\hline Modulus of rupture & $1.52 \mathrm{MPa}$ & Silica & 61 \\
\hline Permanent linear change on reheating for $24 \mathrm{~h} @ 1280^{\circ} \mathrm{C}$ & $1.95 \%$ & Ferric oxide & 1.6 \\
\hline Cold compressive strength & $2.01 \mathrm{MPa}$ & & \\
\hline Thermal conductivity @300 $\mathrm{C}$ & $0.2 \mathrm{~W} / \mathrm{mK}$ & & \\
\hline Thermal conductivity @750 $\mathrm{C}$ & $0.28 \mathrm{~W} / \mathrm{mK}$ & & \\
\hline
\end{tabular}

Table 3. Characterization of porous ceramic burners.

\begin{tabular}{|c|c|c|c|c|c|}
\hline Porous ceramic matrix & Diameter/width (mm) & Thickness (mm) & Pore size (mm) & Ceramic matrix type & Porosity (\%) \\
\hline 1 & 80 & 10 & 1.5 & Circular & 85 \\
\hline 2 & 80 & 15 & 1.5 & Circular & 85 \\
\hline 3 & 80 & 20 & 1.5 & Circular & 85 \\
\hline 4 & 80 & 10 & 1.5 & Circular & 80 \\
\hline 5 & 80 & 15 & 1.5 & Circular & 80 \\
\hline 6 & 80 & 20 & 1.5 & Circular & 80 \\
\hline 7 & 80 & 10 & 1.5 & Square & 85 \\
\hline 8 & 80 & 15 & 1.5 & Square & 85 \\
\hline 9 & 80 & 20 & 1.5 & Square & 85 \\
\hline 10 & 80 & 10 & 1.5 & Square & 80 \\
\hline 11 & 80 & 15 & 1.5 & Square & 80 \\
\hline 12 & 80 & 20 & 1.5 & Square & 80 \\
\hline
\end{tabular}

the reaction zone. For stabilizing the flame at different layers above the surface of the ceramic matrix, the observations obtained by Liu and Hsieh [11] (flame speed in a PHB decreased with an increase in the length of the porous bed) were utilized by optimizing layers of steel balls in the PZ and thickness of $\mathrm{CZ}$ to reduce the speed of the flame within the $\mathrm{CZ}$ corresponding to different velocities of flow.

\subsection{Thermal efficiency tests}

Figure 4 shows a schematic of the thermal efficiency test for three different burners. Thermal efficiency test was conducted using the water boiling test prescribed by BIS 4246:2002. A distance of $50 \mathrm{~mm}$ was maintained between the burner surface and the bottom of the vessel as per the prescribed standard. Thermal efficiency was calculated using Eq. (2) for each input velocity as follows:

$$
\eta=\frac{\left(m_{w} C_{p w}+m_{v} C_{p v}\right)\left(t_{2}-t_{1}\right)}{m_{f} C V}
$$

\subsection{Radiation efficiency}

The radiation efficiency was calculated for different burners corresponding to their respective optimum firing rate. Radiation efficiency was determined from the following relation used by Leonardi et al [12]:

$$
\begin{gathered}
\eta=\frac{Q_{\text {rad }}}{F R} \\
F R=\frac{L C V \times \dot{m}_{f}}{A} \mathrm{~kW} / \mathrm{m}^{2}
\end{gathered}
$$

where $L C V, \dot{m}_{f}$ and $A$ are the heating value, mass flow rate of the fuel and cross-sectional area of the burners, respectively;

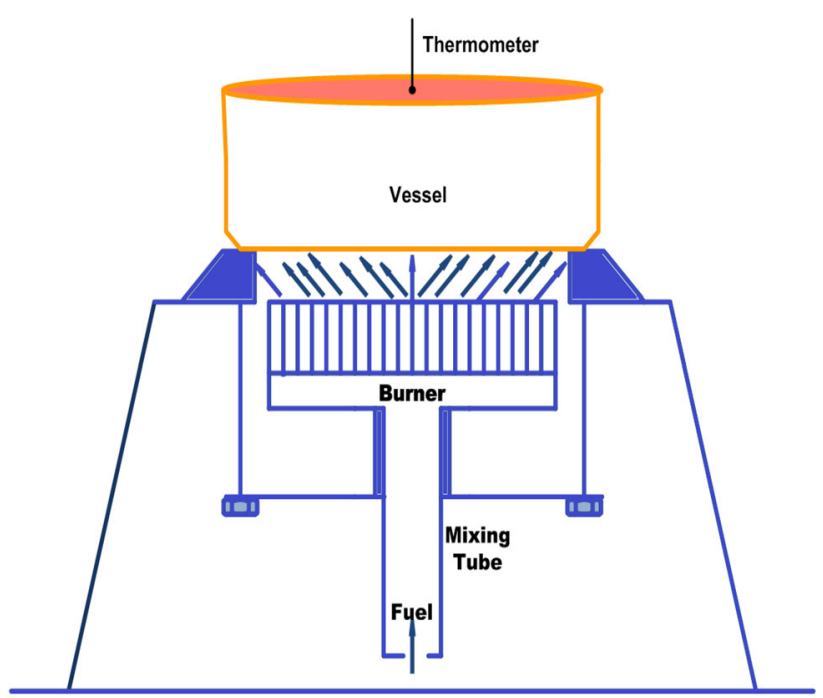

Figure 4. Schematic of thermal efficiency test. 


$$
\dot{m}_{f}=\rho a v
$$

where $\rho$ ' is the density of the fuel, ' $a$ ' is the area of the fuel nozzle and ' $v$ ' is the fuel flow velocity at the nozzle tip. Hence $F R \propto \dot{m}_{f} \alpha v$.

$$
Q_{\text {rad }}=\varepsilon \sigma\left[T_{\text {surf }}^{4}-T_{\text {surr }}^{4}\right]
$$

where the Stefan-Boltzmann constant $\sigma=5.6697 \times 10^{-8}$ $\mathrm{W} / \mathrm{m}^{2} \mathrm{~K}^{4}$ and emissivity $\varepsilon=0.95$ [10]. The radiation efficiency at $2 \mathrm{~m} / \mathrm{s}$ was calculated as $23.11 \%$.

\subsection{Emission test}

The emission tests were conducted in a confined environment. The experimental set-up was designed in such a way that it could be closed all around the burner using an insulating barrier with asbestos sheets of 5-mm thickness except for the exhaust outlet whenever required. During the emission tests, the probe of the flue gas analyser was kept exactly on the top of the flame. Before the emission data were recorded, the gas analyser was left for $30 \mathrm{~s}$ for auto-calibration. The emission results were acquired from the display unit of the analyser as percentage of the $\mathrm{CO}, \mathrm{NO}_{x}, \mathrm{CO}_{2}, \mathrm{HC}$ and $\mathrm{O}_{2}$ and processed in the SCOPE application software environments.

\section{Results and discussion}

\subsection{Thermal efficiency}

The thermal efficiencies of both the CB and the two newly designed self-aspirated porous radiant burners (SCPRB and SSPRB) are computed and plotted in figure 5. The maximum thermal efficiency of the SCPRB is found to be

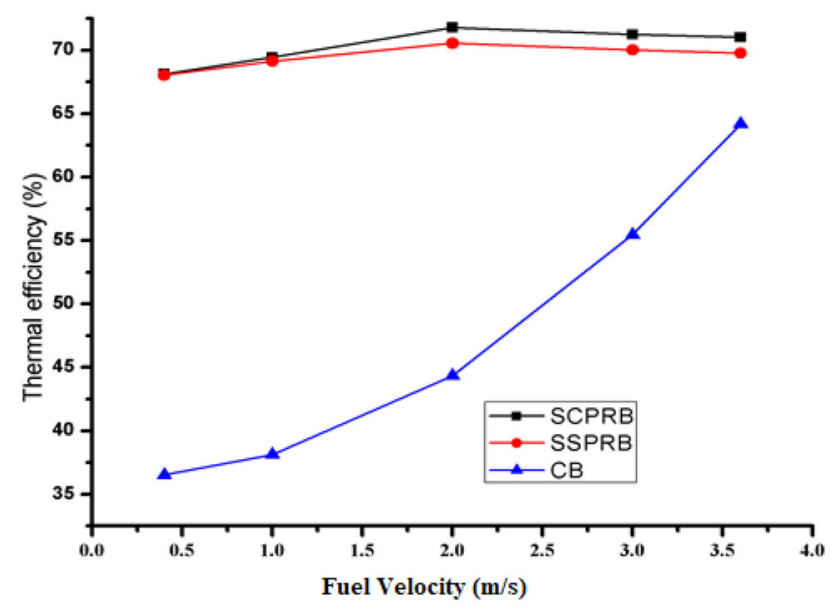

Figure 5. Thermal efficiency vs. firing rate/fuel flow velocity $(\mathrm{m} / \mathrm{s})$.
$71.78 \%$ at the flow velocity $(V)$ of $2 \mathrm{~m} / \mathrm{s}$ and with a porosity of $85 \%$, although thermal efficiency tests are conducted at 5 different input velocities such as $0.4,1.0,2.0,3.0$ and $3.6 \mathrm{~m} / \mathrm{s}$. The thermal efficiencies at other velocities are found to be $68.12 \%$ at $V=0.4 \mathrm{~m} / \mathrm{s}, 69.44 \%$ at $V=1.0 \mathrm{~m} / \mathrm{s}$, $71.23 \%$ at $V=3.0 \mathrm{~m} / \mathrm{s}$ and $71.02 \%$ at $V=3.6 \mathrm{~m} / \mathrm{s}$, whereas the thermal efficiencies obtained from SSPRB are marginally less than those from SCPRB at the corresponding flow rates and porosity. However, for $\mathrm{CB}$ these values are $36.52 \%, 43.65 \%, 48.24 \%, 55.46 \%$ and $64.16 \%$ corresponding to the flow rates of $0.4,1.0,2.0,3.0$ and $3.6 \mathrm{~m} / \mathrm{s}$, respectively, under similar conditions and the maximum thermal efficiency for CB is found to be $64.16 \%$ at the flow rate of $3.6 \mathrm{~m} / \mathrm{s}$. It is also observed that the efficiencies in case of CB gradually increase with the increase in the flow rate from 0.4 to $3.6 \mathrm{~m} / \mathrm{s}$ and then decrease with the increase in flow rate beyond $3.6 \mathrm{~m} / \mathrm{s}$. This is because CBs are generally free flame burners. In case of $\mathrm{CBs}$, combustion reaction is initiated from the bottom surface of the port and a thin reaction zone is formed. Hence, the fuel burns in the open space. Port surface at the top of the burner acts as an igniter for continuous combustion. With the increase in mass flow rate, fuel moves at higher velocities. It does not get sufficient time to have better mixing with air and as the reaction zone is very thin, a mixture of fuel and air burns in the open space with two different types of flames. With a further increase in flow rate (velocity of flow of fuel), the central blue flame propagates in a straight path and approaches bottom surface of the pan. Hence, thermal efficiency of the burner increases with increase in firing rate due to increased heat transfer rate to the load. However, when the firing rate and hence the flow velocity is such that the flame starts impinging the bottom surface of the pan, thermal efficiency of the burner starts decreasing due to flame quenching [13]. In this case, convection is the only dominant mode of heat transfer; with further increase in firing rate, flame produced per unit time from the burner surface may not be completely accommodated on the bottom surface of the pot and thereby more and more amount of heat is lost to the surroundings. In this case, the surface area absorbing the heat plays a vital role for the loss in efficiency [14, 15]. However, in case of two-layered SAPRBs, with the increase in flow, temperature of the mixture increased due to internal heat recirculation [16]. An increase in temperature decreased the primary aeration in the fuel and a fuel-rich mixture was obtained. Hence, the rate of reaction increased with the fuel-rich mixture $[6,15]$ and it shifted the reaction zone further downstream of the $\mathrm{CZ}$. Hence, a trial is made to stabilize the flame within a height of $50 \mathrm{~mm}$ above the burner surface, equalizing the velocity of flow of mixture and rate of reaction. The rate of reaction has been controlled through secondary aeration by natural draft to the burner creating an interfacial gap between the PZ and CZ. The rate of flow is controlled by optimizing layers of steel balls in the PZ and the thickness of CZ. It was also observed from the literature that an 
increase in length of the porous bed increases mass flow rate [10]. An increase in length of PZ beyond certain limit increases the chance of flashback [17-19]. Hence, the optimum length of $\mathrm{PZ}$ is kept at $8-10 \mathrm{~mm}$ with two layers of 5-mm-diameter steel balls and that for $\mathrm{CZ}$ is at $20 \mathrm{~mm}$. With this optimization of the length of both the zones, optimum velocity of flow is obtained at $2 \mathrm{~m} / \mathrm{s}$. This velocity of flow is optimum as the length of the flame remains at $50 \mathrm{~mm}$ above the burner surface. Due to the presence of interfacial gap between $\mathrm{PZ}$ and $\mathrm{CZ}$, there is no conductive heat transfer between them. The partially premixed air-fuel mixture is thoroughly heated to $175-193^{\circ} \mathrm{C}$ as shown in figure 6, corresponding to different velocities of flow due to convective and radiative heat transfer in the upstream direction as well as quenching due to mixing of secondary air. This temperature range remained much below the ignition temperature of the fuel. Hence there is no ignition of fuel in the interfacial gap. Then this mixture is uniformly heated to its ignition temperature while passing through $\mathrm{CZ}$. As metal balls are used in the PZ, flashback effect due to excess preheating of mixture is controlled by optimizing the interfacial gap length between the two zones within a range of $12-15 \mathrm{~mm}$. From the measurement of temperature in the mixing tube close to the $\mathrm{PZ}$, a range of temperature around $52-78^{\circ} \mathrm{C}$ (figure 6) is obtained for the range of input velocities used in the test. This range of temperature of the mixture that is obtained below the PZ confirms that there is no ignition of fuel and hence there is no flashback within the operating range. The transient temperature graph (figure 6) shows a uniform temperature of the flame around $1000^{\circ} \mathrm{C}\left(T_{1}\right)$ and $500^{\circ} \mathrm{C}\left(T_{3}\right)$ corresponding to a height of 0 and $50 \mathrm{~mm}$, respectively, from the burner surface. Also IR

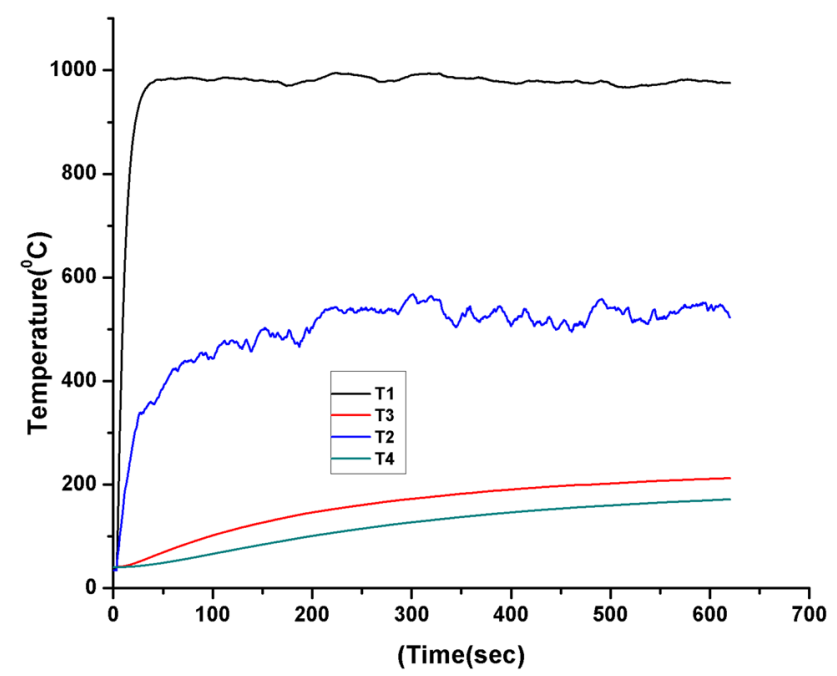

Figure 6. Transient temperature profile at $V=2 \mathrm{~m} / \mathrm{s}$ with $5-\mathrm{mm}$ steel balls, $20-\mathrm{mm}$-thick $\mathrm{CZ}$ and $85 \%$ porosity. $\left(T_{1}\right.$ : axial temperature at a distance of $110 \mathrm{~mm}$ from the burner surface, $T_{2}$ : radial temperature exactly at the circumference of the burner, $T_{3}$ : temperature at the interface of preheating and reaction zone and $T_{4}$ : temperature below the preheating zone.)

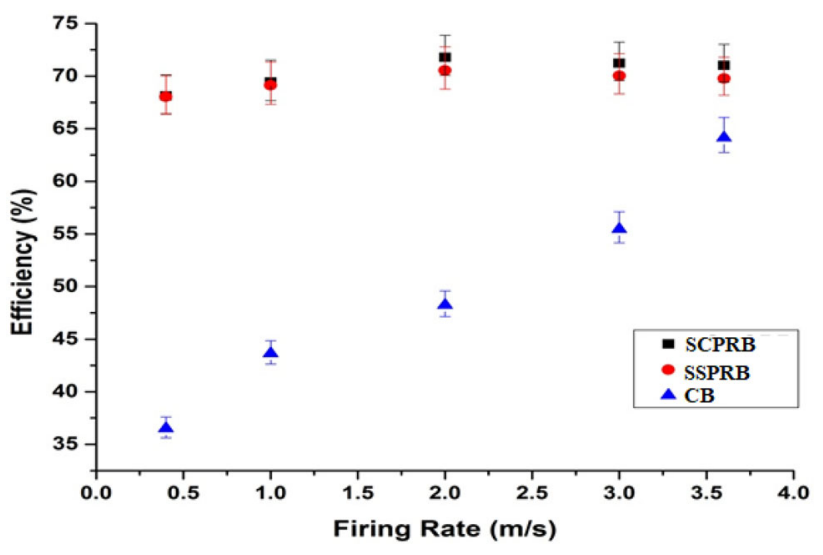

Figure 7. Estimated uncertainty in thermal efficiency.

thermograph (figure 10a and b) represents uniformity in the temperature of the surface due to homogeneity of temperature in the $\mathrm{CZ}$. This uniformity in surface temperature (around $500^{\circ} \mathrm{C}$ ) is produced due to combined (conduction, convection and radiation) mode of heat transport through $\mathrm{CZ}$ and a higher thermal efficiency is obtained in SAPRBs at a lower flow rate compared with $\mathrm{CB}$ with an increase in fuel efficiency as conduction, radiation and convection become the dominant mode of heat transfer in the downstream direction [16-19]. From the result it is obvious that the fuel consumption in the $\mathrm{CB}$ is higher for each input velocity than in the SAPRBs. The estimated uncertainty in thermal efficiency is $\pm 2.34 \%$ corresponding to the flow velocity of $2 \mathrm{~m} / \mathrm{s}$ and is shown in figure 7 .

\subsection{Emission characteristics}

The emission test is conducted in confined environment, keeping the test probe close to the burner top, in order to avoid the effect of excess air induced into the test probe. The observed values of $\mathrm{NO}_{x}$ and $\mathrm{CO}$ for all the burners are depicted in the graph as shown in figures 8 and 9. In case of the $\mathrm{CB}$, the values of $\mathrm{NO}_{x}$ and $\mathrm{CO}$ go on increasing with the increase of the firing rate/velocity of flow as a result of larger combustion rate, incomplete combustion due to less residence time and sharp rise in peak flame temperature $[1-4,18,19]$. In case of $\mathrm{CB}, \mathrm{CO}$ emission increases due to incomplete combustion as a result of less residence time of the mixture in the reaction zone and non-uniformity in the temperature of the flame as shown in figure 10c. The value of the $\mathrm{NO}_{x}$ emission is in the range of 73-101 ppm for CB due to sharp rise in peak flame temperature and in case of SCPRB and SSPRB these values are in the range of 12-32 and 14-40 ppm, respectively, corresponding to equal range of firing rates/velocities as shown in figure 8. The $\mathrm{NO}_{x}$ emission values corresponding to the optimum velocity of $2 \mathrm{~m} / \mathrm{s}$ were $87 \mathrm{ppm}$ for $\mathrm{CB}$ and 24 and $32 \mathrm{ppm}$, respectively, for both SCPRB and SSPRB. In the case of SAPRBs, although the temperature in the $\mathrm{CZ}$ is higher 


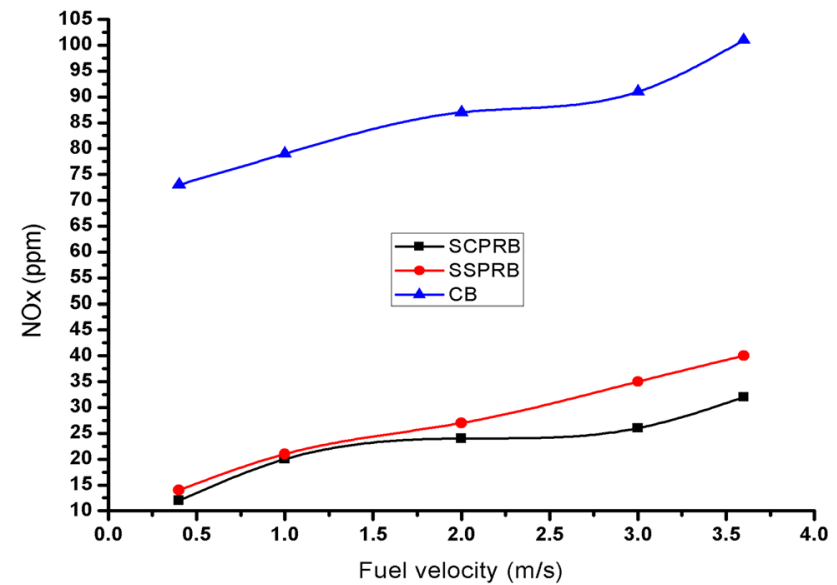

Figure 8. $\mathrm{NO}_{x}$ emission vs. firing rate/fuel flow velocity $(\mathrm{m} / \mathrm{s})$.

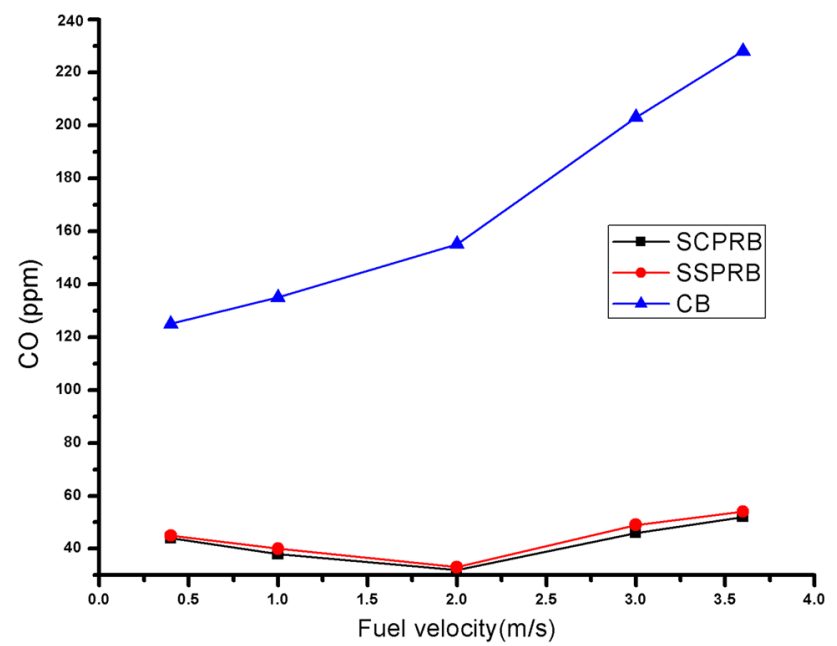

Figure 9. CO emission vs. firing rate/fuel flow velocity $(\mathrm{m} / \mathrm{s})$.

compared with $\mathrm{CB}$, formation of $\mathrm{NO}_{x}$ is low due to uniform heating and slow rise in peak flame temperature [1-4, 18, 19]. Similarly, the CO emission values of the CB are in the range of 125-228 ppm for the considered range of firing rates/velocities. However, these values for SCPRB ranged from 44 to $52 \mathrm{ppm}$ and the corresponding values for SSPRB ranged from 45 to $54 \mathrm{ppm}$ as shown in figure 9. CO emission values in the SAPRBs are less as compared with that of $\mathrm{CB}$. This might be due to better combustion of fuel in the $\mathrm{CZ}$ due to thorough and uniform heating, and high residence time within the $\mathrm{CZ}$ as compared with $\mathrm{CB}$. Another reason for slower but complete combustion is due to secondary aeration in the interfacial gap between PZ and $\mathrm{CZ}$. Higher combustion temperature is one more reason to reduce $\mathrm{CO}[1-4,8,13]$. Both $\mathrm{NO}_{x}$ and $\mathrm{CO}$ emission values of SAPRBs are well within the requirements of World Health Organization (WHO) standards. But $\mathrm{NO}_{x}$ and $\mathrm{CO}$ emissions show different trends corresponding to the rise in power intensity/firing rate/velocity of flow of the fuel.

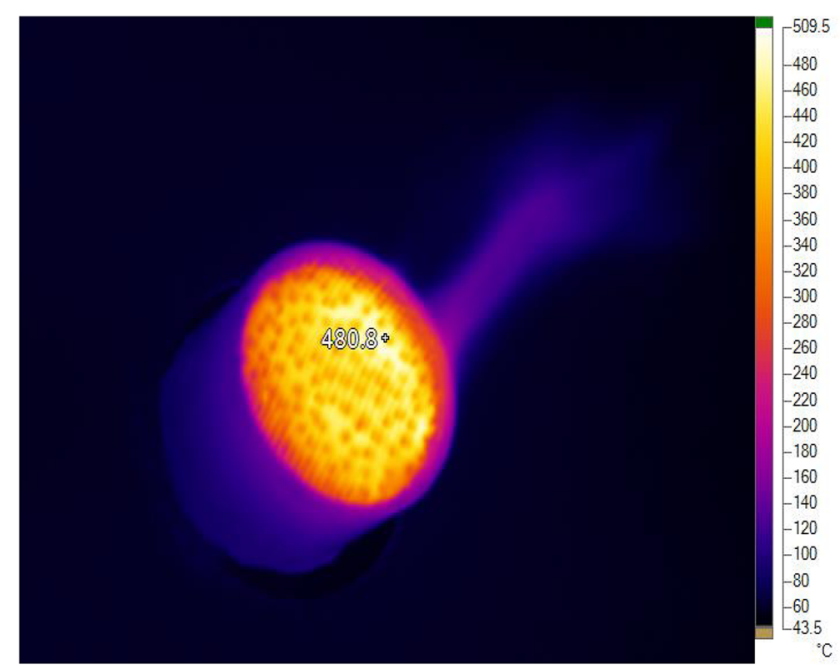

(a) IR image of SCPRB.

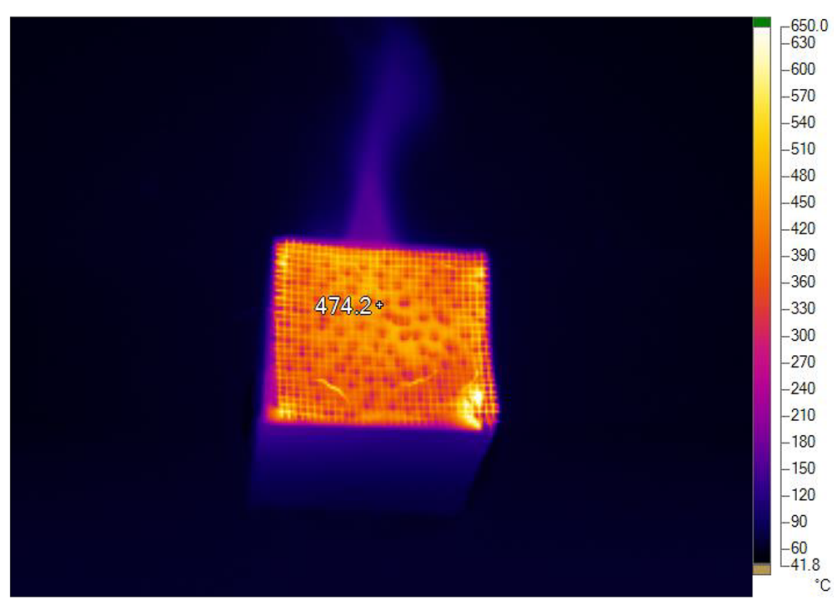

(b) IR image of SSPRB.

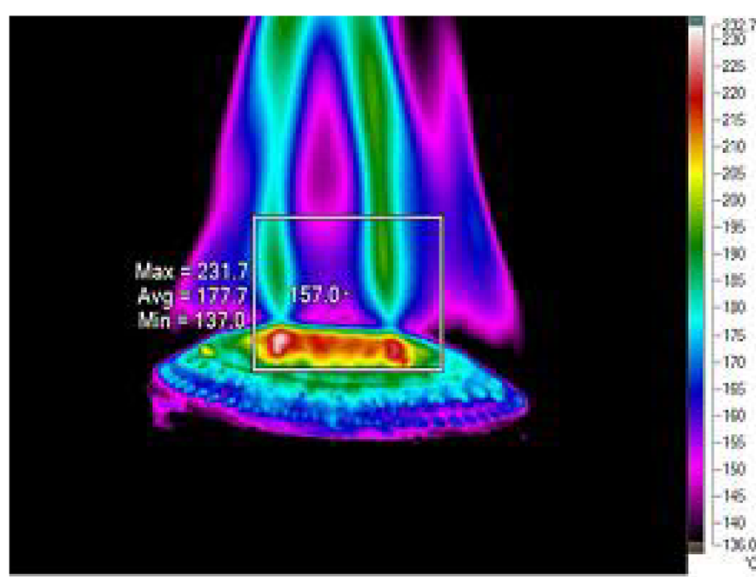

(c) IR image of CB

Figure 10. IR images of the PRBs and $\mathrm{CB}$ at $V=2.0 \mathrm{~m} / \mathrm{s}$.

While $\mathrm{NO}_{x}$ emission continuously increases with the increase in power intensity/firing rate/velocity of flow of the fuel due to rise in temperature of the flame, $\mathrm{CO}$ 
emission decreases at the beginning with the increase in velocity of flow of the fuel up to $2 \mathrm{~m} / \mathrm{s}$ and then rises sharply up to $3.6 \mathrm{~m} / \mathrm{s}$ due to quenching of the flame after impinging the bottom surface of the vessel $[20,21]$.

\subsection{Temperature analysis}

IR image analysis (figure 10) revealed that the average surface temperature of SCPRB is $480.8^{\circ} \mathrm{C}$ and for SSPRB it is around $6^{\circ} \mathrm{C}$ less than that of the SCPRB. This might be due to the structural difference between the two. However, for $\mathrm{CB}$ it is much less, and varies from 145 to $225^{\circ} \mathrm{C}$ with $157^{\circ} \mathrm{C}$ at the centre of the burner surface. Also it has been observed that the distribution of the temperature is more uniform in SAPRBs compared with CB. As CBs are designed for open flames, burner heads are made hemispherical to bend the flames towards the centre with a view to improve thermal efficiency by increasing rate of convection $[5,6,21]$, whereas in case of PRBs with selfaspiration of air, velocity of flow was sufficiently slowed down within the reaction zone due to the increase in thickness of both the layers and secondary aeration at the interface of both the zones. Due to large surface area of the porous matrix, both convection and conduction modes of heat transfer increase. Thereby, convection loss is minimized and ultimately it minimizes cooling effect of the matrix by the flame. Hence, a uniform temperature distribution is obtained in PRBs compared with CBs [22, 23]. As shown in figure 6 , the measured surface temperature is around $500^{\circ} \mathrm{C}\left(T_{3}\right)$ and remained almost constant during the period of operation and the axial temperature at a distance of $50 \mathrm{~mm}$ from the burner surface remained around $1000^{\circ} \mathrm{C}$ corresponding to a flow rate of $2 \mathrm{~m} / \mathrm{s}$. Comparing temperature of both the surfaces, it can also be predicted that the radiation effect was more in porous surface burners compared with $\mathrm{CB}$. In case of $\mathrm{CBs}$, radiation output should be less than $25 \%$ from the burner surface to minimize the loss in thermal efficiency as the distance between the burner surface and the vessel is maintained at $50 \mathrm{~mm}$ [1]. The calculated radiation efficiency is $23.11 \%$, assuming maximum emissivity of the surface as 0.95 . Hence radiation efficiency plays a vital role in optimizing burner surface area corresponding to the bottom surface area of the vessel to enhance thermal efficiency and the selection of material for CZ.

\subsection{Effect of porosity}

The thermal efficiencies of the PRBs are tested at two different porosities of the ceramic material, i.e., $80 \%$ and $85 \%$. The thermal efficiency of the SCPRB at $V=2.0 \mathrm{~m} / \mathrm{s}$ with $80 \%$ porosity ranges around $71.18 \%$; on increasing the porosity from $80 \%$ to $85 \%$, efficiency of the burner is increased to $71.78 \%$. However, a marginal temperature difference of $6.6^{\circ} \mathrm{C}$ with a decrease in efficiency of $0.32 \%$ is observed in SSPRB compared with SCPRB corresponding to the optimum velocity of $2.0 \mathrm{~m} / \mathrm{s}$. Although it is revealed from open literature that an increase in porosity of $\mathrm{CZ}$ increases thermal efficiency of the burner due to increase in conduction and convection mode of heat transfer with the increase in contact surface area, further increase in porosity of the firebrick ceramic might cause higher thermal stress and failure of the burner. Hence, no trial is made beyond $85 \%$ of porosity. It was also observed that there was a marginal increase of $0.86 \%$ in the efficiency of the SCPRB burner with increase in porosity from $80 \%$ to $85 \%$, while no significant change was observed in $\mathrm{NO}_{x}$ and $\mathrm{CO}$ emissions with the increase in porosity within the range of $80-85 \%$.

\subsection{Effect of thickness of ceramic matrix}

In the $\mathrm{CZ}$, three different sizes of ceramic matrices are considered for the efficiency and emission analysis. The thermal efficiencies of the PRBs are tested at different thicknesses of ceramic material, i.e., 20, 15 and $10 \mathrm{~mm}$. The maximum thermal efficiency with 20-mm thickness of ceramic matrix at an optimum flow velocity of $2 \mathrm{~m} / \mathrm{s}$ is $71.78 \%$ for SCPRB and $71.18 \%$ for SSPRB, while for 15 and $10-\mathrm{mm}$-thick matrices the thermal efficiencies for SCPRB are $69 \%$ and $65.34 \%$, respectively, with a marginal decrease reported for SSPRB at the corresponding thicknesses. Referring to the thermo-physical properties (table 2) of ceramic base, thermal heat capacity increases with the increase in thickness of the porous matrix $[9,10]$. Also, it is observed that increase in length of the porous bed increases mass flow rate of the fuel; thereby, higher velocity of flow is required to overcome friction with the increase in thickness of the ceramic matrix [11]. Hence, 20-mm-thick ceramic matrix in CZ might be optimum for the corresponding operating conditions used in the experiment. The values of $\mathrm{NO}_{x}$ and $\mathrm{CO}$ are in the range of 29-47 and 60-95 ppm, respectively, for different thicknesses of the ceramic matrix at the optimum flow velocity of $2 \mathrm{~m} / \mathrm{s}$. $\mathrm{NO}_{x}$ and $\mathrm{CO}$ emission values corresponding to optimum flow velocity of $2 \mathrm{~m} / \mathrm{s}$ with the use of 5-mm-diameter steel balls in the PZ and $85 \%$ porosity of $\mathrm{CZ}$ are 24 and 32 ppm, respectively.

\subsection{Effect of stainless-steel balls}

Two different sizes of stainless-steel balls are used in the PZ and their effect on thermal efficiency and emission from the burner are studied. It is observed that the maximum thermal efficiency at $V=2.0 \mathrm{~m} / \mathrm{s}$ for the 5-mm-diameter of steel balls is $71.78 \%$ and $\mathrm{NO}_{x}$ and $\mathrm{CO}$ emissions are 24 and $32 \mathrm{ppm}$, respectively, while flashback effect is observed with 3-mm-diameter steel balls. Due to preheating of the 
mixture, primary aeration in the mixture is very low [6] and hence rate of reaction is larger. With the use of 3-mm balls, flow passages for the gas were sufficiently decreased further downstream of the PZ. The flame is unable to propagate through the passage of the balls in the downstream direction. A high-temperature convection wave is set up; there is a rise in temperature of the mixture and the flashback effect is observed with the use of $3-\mathrm{mm}$ balls.

\subsection{Effect of confinement on thermal efficiency and emission}

Confinement is the controlled atmosphere created around the burner using an insulated barrier between the burner and the open atmosphere. This is the space formed around the burner, enclosing all the four sides and base of the burner with a 5-mm-thick asbestos sheet and the top of the burner with a conical hood. The conical hood on the top is fitted with a tube of 40-mm diameter for exhaust gas outlet. During water boiling test, when the water vessel was heated, temperature within the set-up remained $5-10^{\circ} \mathrm{C}$ higher than that of the atmosphere as there was no direct heat communication between the open atmosphere and the enclosed space around the burner. Thus, the loss of heat due to convection and radiation is reduced to the minimum. Hence, a $2 \%$ higher thermal efficiency is observed compared with an open environment. It is also revealed from the open literature that thermal efficiency of the burner increases with the increase in atmospheric temperature $[1,3,23,24]$. No significant change in $\mathrm{NO}_{x}$ and $\mathrm{CO}$ emission is observed corresponding to the flow velocity of $2 \mathrm{~m} / \mathrm{s}$.

\subsection{Effect of geometry of the burners}

As shown in figure 5, at lower velocities of flow, such as 0.4 and $1.0 \mathrm{~m} / \mathrm{s}$, there is no significant change in thermal efficiency of SAPRBs with respect to change in geometry (circular and square) of the burners. At higher firing rate, a little rise in thermal efficiency of SCPRB is observed as compared with SSPRB, which is in the order of 1.2-1.24\%. This change is very small and is almost negligible. Comparing $\mathrm{NO}_{x}$ emission from both the burners (figure 8), it is observed that $\mathrm{NO}_{x}$ emission from SSPRB increases almost linearly with the rise in the flow rate of the fuel. However, the SCPRB burner shows a different trend compared with SSPRB, although a similarity in rising of $\mathrm{NO}_{x}$ pattern is observed between CB and SCPRB. A significant difference in $\mathrm{NO}_{x}$ emission is observed between SSPRB and SCPRB at higher velocities, i.e., beyond $2 \mathrm{~m} / \mathrm{s}$. This difference in $\mathrm{NO}_{x}$ emission at higher firing rate/velocity of the flow might be due to the structural or geometric difference of the two. No difference in pattern and an insignificant difference in the values of $\mathrm{CO}$ emission are obtained due to difference in geometry of the burners (figure 8). Hence, it can be concluded that geometry has a marginal/little effect on thermal efficiency and $\mathrm{CO}$ emission of the burners, but at higher velocities or firing rate, $\mathrm{NO}_{x}$ is dependent on structure.

\section{Conclusion}

- Open literature revealed that the conventional burners used in cooking purposes are not much efficient and result in high carbon footprint. So far, any development made in domestic CBs using PMC was meant for the lean combustion; however, in the present work, PMC is used to reach combustion, as a rich mixture is always expected in a naturally aerated burner.

- In most of the two-layered porous burners, the preheating and CZs are continuous, i.e., the materials used in these zones are in contact with each other, leading to the dominant effect of heat conduction in the upstream direction. In this work, a gap of $12-15 \mathrm{~mm}$ is maintained between the PZs and CZs, which reduces the conduction effect in the PZ and exhibits dominant convection effect.

- The newly developed SCPRB and SSPRB are found to be more efficient as compared with CBs. The thermal efficiencies of SCPRB at different flow rates $(V)$ of 0.4 , $1.0,2.0,3.0$ and $3.6 \mathrm{~m} / \mathrm{s}$ are, respectively, $31.6 \%$, $25.79 \%, 23.54 \%, 15.77 \%$ and $6.86 \%$ more than that of $\mathrm{CB}$ at $85 \%$ porosity level. The thermal efficiencies obtained from SSPRB are marginally less than those of SCPRB at the corresponding flow rates and porosities.

- The value of the $\mathrm{NO}_{x}$ emission is in the range of 76-102 ppm for CB and in case of SCPRB and SSPRB these values are in the range of 12-32 and 14-40 ppm, respectively, corresponding to equal ranges of flow. The $\mathrm{CO}$ emission values of the $\mathrm{CB}$ are in the range of 125-228 ppm for the considered range of flow. However, the values $\mathrm{CO}$ for SCPRB ranged from 44 to $52 \mathrm{ppm}$ and that of SSPRB ranged from 45 to $54 \mathrm{ppm}$.

- There is a marginal increase of $0.86 \%$ in thermal efficiency of the SCPRB burner with increase in porosity from $80 \%$ to $85 \%$ corresponding to an optimum velocity of $2 \mathrm{~m} / \mathrm{s}$.

- Geometry of the burner has a little or marginal effect on the efficiency and emission of the burner.

- An increase in efficiency around $2 \%$ is obtained due to confinement.
Nomenclature
$\mathrm{CO}$ carbon monoxide
$\mathrm{CO}_{2}$ carbon dioxide
$\mathrm{CV}$ calorific value of the fuel
$C_{p w} \quad$ specific heat of water 


$\begin{array}{ll}C_{p v} & \text { specific heat of vessel } \\ \mathrm{HC} & \text { hydrocarbon } \\ \mathrm{lpm} & \text { litres per minute } \\ m_{w} & \text { mass of water } \\ m_{v} & \text { mass of the vessel } \\ \mathrm{NO}_{x} & \text { nitrogen oxides } \\ \mathrm{O}_{2} & \text { free oxygen } \\ t_{2} & \text { final temperature of water } \\ t_{1} & \text { initial temperature of water } \\ \alpha & \text { proportional }\end{array}$

\section{References}

[1] Pantangi V K, Mishra S C, Muthukumar P and Reddy R 2011 Studies on porous radiant burners for LPG (liquefied petroleum gas) cooking applications. Energy 36: 6074-6080

[2] Muthukumar P and Shyamkumar P I 2013 Development of novel porous radiant burners for LPG cooking applications. Fuel 112: 562-566

[3] Muthukumar P 2011 Performance analysis of porous radiant burners used in LPG cooking stove. Int. J. Energy Environ. 2: $367-374$

[4] Mishra N K, Muthukumar P and Mishra S C 2013 Performance tests on medium-scale porous radiant burners for LPG cooking applications. Int. J. Emerg. Technol. Adv. Eng. 3: 126-130

[5] Jugjai S, Tia S and Trewetasksorn W 2001 Thermal efficiency improvement of an LPG gas cooker by a swirling central flame. Int. J. Energy Res. 25: 657-674

[6] Namkhat A and Jugjai S 2010 Primary air entrainment characteristics for a self-aspirating burner: model and experiments. Energy 35: 1701-1708

[7] Jugjai S and Rungsimuntuchart N 2002 High efficiency heatrecirculating domestic gas burners. Exp. Therm. Fluid Sci. 26: $581-592$

[8] Yoksenakul W and Jugjai S 2011 Improvement of thermal efficiency of heat-recirculating gas burner. D. Eng. Thesis, Department of Mechanical Engineering, King Mongkut's University of Technology, Thonburi (KMUTT)

[9] Kline S J and Mc Flintlock F A 1953 Describing uncertainties in single-sample experiments. Mech. Eng. 75(1): 3-8

[10] Holman J P 2001 Experimental methods for engineers, 7th ed. Boston, USA: McGraw-Hill

[11] Liu F J and Hsieh W H 2004 Experimental investigation of combustion in porous heating burners. Combust. Flame 138: 295-303
[12] Leonardi A S, Viskanta R and Gore P J 2002 Radiation and thermal performance measurements of a metal fiber burner. J. Quant. Spectrosc. Radiat. Transf. 73: 491-501

[13] Cho S W, Kim Y S, Jeon C H and Chang Y J 2010 An experimental study on the performance optimization of a radiant burner with a surface flame structure. J. Mech. Sci. Technol. 24: 923-929

[14] Catapan R C, Oliveira A A M and Costa M 2011 Nonuniform velocity profile mechanism for flame stabilization in a porous radiant burner. Exp. Therm. Fluid Sci. 35: 172-179

[15] Wu C Y, Chen K H and Yang S Y 2014 Experimental study of porous metal burners for domestic stove applications. Energy Convers. Manag. 77: 380-388

[16] Sathe S B, Peck R E and Tong T W A 1990 Numerical analysis of heat transfer and combustion in porous radiant burners. Int. J. Heat Mass Transf. 33: 1331-1338

[17] Barra A J, Diepvens G, Ellzey J L and Henneke M R 2003 Numerical study of the effects of material properties on flame stabilization in a porous burner. Combust. Flame 134: 369-379

[18] Mishra N K, Mishra S C and Muthukumar P 2015 Performance characterization of a medium-scale liquefied petroleum gas cooking stove with a two-layer porous radiant burner. Appl. Therm. Eng. 89: 44-50

[19] Mishra N K, Muthukumar P and Mishra S C 2013 Performance tests on medium-scale porous radiant burners for LPG cooking applications. Int. J. Emerg. Technol. Adv. Eng. 3: 126-130

[20] Ashman P J, Junus R, Stubington J F and Sergeamt G D 1994 The effects of load height on the emissions from a natural gas-fired domestic cooktop burner. Combust. Sci. Technol. 103: 283-298

[21] Hou S S and Ko Y C 2004 Effects of heating height on flame appearance, temperature field and efficiency of an impinging laminar jet flame used in domestic gas stoves. Energy Convers. Manag. 45: 9-10, 1583-1595

[22] Catapan R C, Oliveira A A M and Costa M 2011 Nonuniform velocity profile mechanism for flame stabilization in a porous radiant burner. Exp. Therm. Fluid Sci. 35: 172-179

[23] Francisco Jr. R W, Rua F, Costa M, Catapan R C and Oliveira A A M 2009 On the combustion of hydrogen-rich gaseous fuels with low calorific value in a porous burner. Energy Fuels 24: 880-887

[24] Francisco Jr. R W, Costa M R, Catapan C and Oliveira A A M 2013 Combustion of hydrogen rich gaseous fuels with low calorific value in a porous burner placed in a confined heated environment. Exp. Therm. Fluid Sci. 45: 102-109 